things to eat and drink, she was abusing me and my family. In short, her temper and her wilful misconstruction of every. thing said and done became so intolerable that, finding it im possible to control her sensual appetites, I determined to send her back to you; and I pray you do not be a party to placing her with any one else. If her relatives wish to try her, let them take her. The difficulty, in a private family, of keeping her from stimulants, must be insuperable; for the strictest directions may be given to servants, but they, for their own peace and quiet, will always be found willing to supply her cravings."

This patient was ultimately discharged, more to escape from the importunities of the Commissioners in Lunacy than from any other cause. She went to her relatives: they could not live with her, and sent her to London to another relation. She there, after a month's residence, clandestinely married a worth less foreigner, who sought her for her annuity, which he speedily managed to extort from her family. What has since becom of her, I cannot tell; but, in all probability, he has placed her in some French asylum for a trifling sum, whilst he is fatten ing upon her income. She had many insane ideas concernin herself, her position in life, and her family, which gradually disappeared.

Many more cases might be added to these, but these suffice to mark a class the most difficult to deal with, because they are always sane in asylums, and always relapse when they get out. They invariably succeed in obtaining their discharge by working upon the fears or feelings of their relatives, and the sympathies of commissioners or visitors, who think them sane because, being under control, they cannot exhibit their propensities; and who tell proprietors of asylums that patients so improved cannot be detained. The real answer is, that they are not improved: they appear sane, because they have not the power or opportunity to be otherwise. Give them that power, and they are lost; as in these cases. They cannot keep up the good habits they learned in control, and they become worse in their second state than in their first. They are much to be pitied, for their friends and acquaintances think them wicked and vicious when they are only mad; and their misconduct is never looked upon as disease, partly because the general practitioners of the kingdom are not sufficiently acquainted with this class of disorders to be able to point out to their relatives the necessity of placing them in control, and to prove to them that disease, not vice, is the true solution of their misconduct. I have read these cases in the hope that practitioners will recognise similar cases as insane, and take the earliest steps to control them, and save them from the consequences of indulgence in their propensities. I cannot say that they are curable cases, as a general rule; they undoubtedly are so occasionally but at large they rapidly become worse, lose all sense of decency and propriety, and end their lives either by suicide or by the consequences of their conduct in the production of fatal disease. There is no hope for them except in control, and that not for the limited periods we are now able to detain them, but until better habits have become so customary as to take the place of their evil habits. Nothing short of this will suffice; and the difficulty of doing this lies in the fact that this form of disorder is rarely recognised by any except those engaged in this branch of medicine. But we require (we might say much more truly that these unfortunate people require) the assistance of general practitioners, to enable us to press strongly upon the friends of such patients the absolute necessity of long continued seclusion.

Few men, engaged in this department of medicine, like to hold strong language to relations, as it is most difficult to convince them that the chief object is the benefit of the patient, not the self-interest of the proprietor; yet it is truly the difference between comfort and misery, and often between life and death, to the patient. If general practitioners could only be brought to see these cases in the same light, how much easier would be the task of convincing the friends, and how much the advantage of the patient's relatives! Take Case I. Two thousand pounds would have been saved to his children, as well as a good business which his widow might have easily managed or sold for a large amount of money. In Case Irr, the evil of suffering the patient to be loose on society was not confined to himself, but produced all kinds of vice and immorality on board of the ship, amongst the emigrants, to such an extent as to attract the notice and censure of both Houses of Parliament In Case Iv, shortly after her discharge, the patient is found making a disgraceful runaway match with a needy, money hunting, soap-abhorring French fiddler, doubtless laying up for herself misery for a lifetime. Can any one say that a life of confinement in a modern asylum, in comfort and decency, is not a life of happiness, compared with the wretchedress produced by indulgence in such diseased and doprived tistes; arid that it is not a duty to detain them in control, and save them from themselves?

I am sure that, if these cases were better recognised by the public, they would be soon remedied. They are by no merns rare-quite the contrary, they are common; and are at all times most difficult to deal with, but surely they ought not to be; and if the same patient investigation and shrewd discrimination were exhibited by general practitioners in these disorders, which they employ in their common cases, these unhapny people would always be more fitly treated, and their relatives more alive to the true requirements of their condition.

\section{THE WATERY DISCHARGES OF PREGNANT WOMEN.}

By I. Harrinson, Esq., F.R.C.S.

[Read before tye Reading Pathological Society.]

UNDER the term "hydrorrhoa uteri gravidarum", "the drib. bling of the waters", etc., a somewhat rare affection has been described, to which pregnant females are subject. The amount discharged, it is said, varies from ounces to pints a day; and the discharge is described to be uniform and colourless. The source has been considered to be the vagina, the space between the membranes; and, as I understand Dr. Rigby, the membrane which lines the cavity of the uterus. Dr. Davis says it is in most cases "a dangerous, and often a fatal affection". Dr. Churchill says, "This opinion is at variance with other authorities, who do not generally consider this disease as of so serious a character."

I have met with two cases of watery discharge during pregnancy.

CASE I occurred in a healthy woman, aged 38 , in her ninth pregnancy. From the end of the first month she had a constant discharge, beginning with a coloured, and followed by a profuse watery one, saturating three or four or more napkins daily. These alternated, at intervals of a few days, to the full period. There was no diminution of size apparently induced. Labour was ushered in by a bloody discharge, more profuse than usual: as it advanced, a small portion of the placenta was found presenting. Labour was completed rapidly, naturally, and favourably. The child was alive. Unfortunately, no description of the placenta is given in my notes.

CASE Ir. A feeble woman, in ill health, aged 38, in her tenth pregnancy, had slight discharge at the end of the second month; more at the end of the third month; and from this time to the end of the sixth month she had it more or less coloured or watery. For the first two weeks of the seventh month, she was under treatment, by which the discharge was arrested. During this time I carefully examined her, but found nothing abnormal. When under supervision, the discharge was entirely watery. After treatment was discontinued, the discharge returned, and labour was ushered in at the end of the seventh month by a sudden coloured discharge, to the amount of a pint. On examination, a thin edge of the placenta was found occupying one-fourth of the circumference of the os uteri, now open to the size of a florin. By the means used, the os uteri rapidly became dilated; and the child, breech presenting, was easily born: it had been dead some days. The placenta was quickly removed, without any unusual hæmorrhage. On examining the placenta, there was seen attached to one edge $\mathbf{a}$ considerable quantity of fibrine, showing undoubtedly the separated portion. The cord was only eight and a half inches long.

I maintain that, in these two cases, the placenta was attached in the immediate neighbourhood of the os uteri; that, at an early period of pregnancy, a portion of the placenta became detached; and that from the opposed and separated surfaces the coloured and watery discharges issued. I do not mean positively to assert that these cases are similar to those given on authority in the first part of my paper, though I strongly suspect that the $z$ are. It is somewhat singular that, in the recorded cases, no mention is made of any coloured discharge, nor any remark as to the state of the placenta. If the classes are similar, the cases related afford a new version of the source of the discharge; if dissimilar, they supply an important deficiency in the history of watery discharges in pregnant females. Whether similar or dissimilar, they show that both 
Dr. Davis and the more numerous dissentient authorities may both be right; that the cases may terminate favourably; and also that they may be beset with peril.

\section{ON GE N E A L B L E E D N G.}

By H. Wilkinson, Esq., Rotherham.

[Read before the Yorkshire Branch, June 4th, 1857.]

Is bringing the subject of general blood-letting before the notice of this meeting, I am aware that I am treading on very delicate ground. But, as Lord Bacon has said, "Human experience, which is constantly contradicting theory, is the great test of truth"; and, as I do not intend to introduce anything but facts, letting alone theory, I shall not expose myself to severe criticism from those who may think differently.

The propricty of blood-letting, particularly venesection, has undergone considerable modification in the minds of practitioners in late years. What has occasioned this change of opinion, I am at a loss to know; for my own part, I am more and more convinced of the value of the remedy, and am often reminded of the remark I once heard from the late Dr. Younge, of Sheffield: "That he had often had to regret not having taken sufficient blood, but seldom, very seldom, that he had taken too much."

Many gentlemen are of opinion that the aspect or type of disease has changed, and that we have no longer that acut form of disease we used to see. These altered views may account in some measure for the disuse of the lancet in those who entertain them. Another reason may be, that the patient may have been bled once during the attack, with relief to the symptoms, but, reaction having returned requiring a second venesection, and that not being carried out, the patient has died, and the lancet has been blamed for the want of decision on the part of the practitioner. Whatever others may think, however, in reference to the altered aspect of disease, I confess that I am so dull or so blind that I cannot see it; on the con trary, I am more and more satisfied of the truth of Dr. Younge's remark, and every day's experience induces me to believe that the remedy admits of much more extensive application than it has ever yet met with, unless we are to believe Gil Blas, when he tells us that Dr. Sangrado bled all his patients till they died, and then declared that they had not lost enough blood. I fear, however, judging from the spirit of the medical journals, and from thase whom I frequently meet, that blood-letting has undeservedly fallen into disrepute; and for that reason, I will do the best I can to save it from perdition; cunvinced, as I am, that where depletion is really indicated, there is no substitute for the lancet; and the patient, when suffering from an acute inflammatory disease, must die, unless depletion be freely carried out

But, as I have already said, the spirit of the profession is opposed to this practice. As an instance of this, I was par ticularly astonished, about a year and a half ago, in reading in the Lancet, of a paper being read at one of the medical societies, wherein the author came to the strarge conclusion, that pneumonia was an adynamic disease; and what surprised me still more was the circumstance, that in so learned a society, no one should venture to criticise such singular views. If the gentleman believes that all diseases are adynamic, I can go with him to a certain extent; but if he means to classify pneu monia with syncope, hypochondriasis, and the like, according to Cullen, then I should say that these are certainly most dis similar. Indeed, there is scarcely one inflammatory disease, when acute, which admits of a greater amount of depletion than pneumonia; and although I am aware that some members in the profession maintain that it can be cured without bleeding, I an ready to prove that it can be cured much more speedily and with much less risk with it.

Having introduced the sulject of my paper, I will bring before the meeting a living illustration of the value of bloodletting, in a patient of a most unlikely appearance to bear or require such a remedy.

CASE I. S. G., aged 46, a weak spare man, had suffered from asthma for a long time, when he consulted me for a violent paroxysm of the disease, attended with bronchitis. To all appearance, he cou'd not have lived many hours with such violent dyspnoe; when I proposed bleeding in the arm as a last resource, which he bore freely, without fainting, and which gave him instant relief. He has been bled from the arm twenty-eight times within the last ten years, always with the same amount of relief; and although he still suffers from the asthma, he con. siders himself in better health than he has been for several years past. I bring this case forward in proof of the wide field of disease in which blood.letting is applicable, both inflamma. tory and congestive.

I will next give an outline of what I will designate as three extraordinary cases, treated in an extraordinary manner.

Case II. On November 26th, 1855, I was sent for to a little girl, aged 8 years, who was suffering from anasarca as a sequel of scarlatina. She was frequently sick and vomiting, but complained of no other uneasiness. After diuretics had been ad. ministered for four days without relief, she began to complain of dull pain in the head; and as I considered the vomiting to arise from the state of the brain likewise, I gave the alarm to her parents (highly respectable and intelligent people), and advised that the head should be shaven, and a blister applied to each temple. On the night of the same day, about ten o'clock, I was bastily summoned to this child, in consequence of convulsions having suddenly supervened. After the fit had continued unabated for two hours without intermission, I thought it high time to do something decisive if I intended to save my patient; with this view, I requested her mother to bring a fillet and basin, and took from her arm, in the semierect position, no less than twenty-six and a half ounces of blood. I would here observe, that in such acute cases, I always bleed with my finger on the pulse until the heart's action falters, or I should exhaust my patient to little effect. This bleeding had the effect of removing the sickness at once : the convulsions gradualiy ceased, and in a few days were entirely gone. I may say, that in this case, we found great benefit, after the bleeding, in the use of croton oil, which was given for several days as a purgative until the dropsy was removed. She thoroughly recovered within nine days after the bleeding, and has remained well ever since.

CASE III. A brother of this young lady, aged 9 years, was taken with sickness on the day I was first sent for to her. He had a mild attack of scarlatina, with very slight rash; anasarca followed, and on December 2:3rd, twenty-seven days from the first, violent convulsions having set in, I bled him from the arm to seventeen ounces; the convulsions ceased, and never returned; he continued to take aperients and diuretics for about six days after, and then quite recovered, and remained well.

Case Iv. Another little sister of the above, aged 5 rears, had so slight an attack of the disease that fever and anasarca were scarcely perceptible till December $2 !$ th, when convulsions came on after complaining for a few hours of pain in her head. I took from this child's arm thirteen and a half ounces of blood; the convulsions ceased; and she appeared well, till January $3 \mathrm{rd}$, five days afterwards, when the convulsions having returned, I bled her a second time, to the amount of about eight ounces more, which again removed the fits; consciousness returned after the first sleep; she got quite well in a few days, and has continued so up to the present time.

I ought to observe, that in every case the head was shaven, and cold applied.

I leave to my hearers the privilege of forming their own opinions as to the propriety of the treatment pursued.

\section{CASE OF MONSTROSITY.}

By Charies Murray, Esq., Oldham.

ON Thursday, June 4th, 1857, A. C. was safely delivered of a full grown healthy child. It is perfectly formed; the limbs are all complete and well developed. But from between the sternum and umbilicus projects the body of another and smaller child. It is all complete, except the upper extremities, which are merely rudimentary, and the head, which is wanting. The parasitical child is a male, like the larger one. It is endowed with penis and scrotum; but the urethra, if there be any, is closed; and the unus is imperforate.

The infant has thriven from the time of its birth; and nothing has prevented the due performance of the natural functions of the body. It is disturbed, and cries, when the body of the other is handled.

Dr. Ramsbotham, in the appendix to his work on midwifery, gives some similar examples of monstrosity. The first is one of a Chinese, named A-Ke, 16 years old; a second, mentioned by Ambrose Paré ; a third by Palfyn; and a fourth by Winslow. Some of these children lived many years.

As far as appearances enable one to judge, the child I have described promises to do well. 